\title{
Calculations of solubilities of aromatic compounds in supercritical carbon dioxide
}

Yu Jane Sheng, Ping Chin Chen, Yan Ping Chen, and David Shan Hill Wong

Ind. Eng. Chem. Res., 1992, 31 (3), 967-973 • DOI: 10.1021/ie00003a044

Downloaded from http://pubs.acs.org on November 24, 2008

\section{More About This Article}

The permalink http://dx.doi.org/10.1021/ie00003a044 provides access to:

- Links to articles and content related to this article

- Copyright permission to reproduce figures and/or text from this article 
of 2000 and was border line with respect to turbulent flow. The jet twisted or flickered at this flow, and slightly higher flow rates gave turbulence. For smaller nozzles, excessive turbulence at the tip was observed at calculated Reynolds numbers of 1000 . The TCE flow to the nozzle was cooled to $20^{\circ} \mathrm{C}$ and the nozzle discharged into a column of hot TCE for internal gelation of the drops. Useful tests were made with this two-fluid nozzle arrangement. The size distributions showed $D_{84} / D_{\mathrm{p}}$ values of $1.03-1.05$. The single-fluid nozzles above the TCE surface were found to give simpler operation, higher capacities, and slightly better size uniformities.

\section{Conclusions}

The gel-sphere processes require the formation of liquid drops of controlled and uniform sizes at rates of $10^{3}-10^{7}$ drops $/ \mathrm{min}$. The product spheres allow good measurements of the drop size distributions. The basic technique reported here uses an applied vibration to give a controlled and uniform breakup of laminar liquid jets into drops. Controlled alternating current powers the small electromechanical vibrators to apply vibrations to liquid jets in several different ways.

A highly regular and reproducible breakup occurs for vibration frequencies that promote a breakup near the natural frequency of breakup for the laminar jet. With optimum conditions, the drop formation is so regular that the motion appears to be completely stopped when observed with a stroboscopic light.

Criteria are given in this paper for selection of jet diameters, jet velocities, vibration frequencies, and the configurations of the drop-formation apparatus. Selection of these parameters for a specific gel-sphere process involves some compromises to minimize the observed problems by empirical adjustments. Preparation of gelsphere samples required repeated runs in which the drop formation was controlled and reproduced without difficulty. Examples of these results and conditions are given. The values of $\sigma=D_{84} / D_{\mathrm{p}}$ (the geometric standard deviations for a log-normal distribution) were 1.01-1.05.

\section{Literature Cited}

Bischoff, K.; et al. "Sol-Gel Processes for Carbide Preparation". Proceedings of a Panel: Sol-Gel Processes for Fuel Fabrication, Vienna, May 21-24; International Atomic Energy Agency: Vienna, 1974; IAEA-161; pp 95-128.

Haas, P. A. Formation of Liquid Drops with Uniform and Controlled Diameters at Rates of $10^{3}$ to $10^{5}$ Drops per Minute. AIChE J. 1975,21 (2), 282-285.

Haas, P. A. Turbulent Dispersion of Aqueous Drops in Organic $\mathrm{Li}$ quids. AIChE J. 1987, 33 (6), 987-995.

Haas, P. A.; Clinton, S. D. Preparation of Thoria and Mixed-Oxide Microspheres. Ind. Eng. Chem. Prod. Res. Dev. 1966, 5, 236-244.

Haas, P. A.; et al. Preparation of Reactor Fuels by Sol-Gel Processes. Chem. Eng. Prog. Symp. Ser. 1967, 63 (80), 16-27.

Haas, P. A.; et al. Chemical Flowsheet Conditions for Preparing Urania Spheres by Internal Gelation. Ind. Eng. Chem. Prod. Res. Dev. 1980, 19, 459-467.

Merrington, A. C.; Richardson, E. G. The Break-up of Liquid Jets. Proc. Phys. Soc. 1947, 59, 1-13.

Zimmer, E.; et al. Aqueous Chemical Processes for the Preparation of High Temperature Reactor Fuel Kernels. Radiochim. Acta 1978, 25, 161-169.

Received for review August 7, 1991 Revised manuscript received November 4, 1991 Accepted November 28, 1991

\title{
Calculations of Solubilities of Aromatic Compounds in Supercritical Carbon Dioxide
}

\author{
Yu-Jane Sheng, Ping-Chin Chen, and Yan-Ping Chen* \\ Department of Chemical Engineering, National Taiwan University, Taipei, Taiwan, Republic of China \\ David Shan Hill Wong \\ Department of Chemical Engineering, National Tsing Hua University, Hsinchu, Taiwan, Republic of China
}

Solubilities of five aromatic compounds in supercritical carbon dioxide are calculated in this work by using the Patel-Teja equation of state. Unlike the traditional van der Waals mixing rules, the energy parameter of the equation of state is evaluated by equating the excess free energy calculated by the equation of state to that from a UNIFAC group contribution liquid model. New UNIFAC group interaction parameters of carbon dioxide and various hydrocarbon groups are obtained through regression of experimental vapor-liquid equilibrium data. A new mixing rule for the excluded volume parameter of the equation of state is proposed, and a generalized correlation of that parameter is presented. With the new mixing rules, solubilities of aromatic solids in supercritical carbon dioxide can be calculated satisfactorily. The results are comparable to those computed by using the van der Waals mixing rule with multiple best-fitted unlike pair parameters.

\section{Introduction}

Supercritical fluid extraction (SCFE) is a new separation technology which has received much interest in the processing of pharmaceuticals, natural products, and many other special applications (McHugh and Krukonis, 1986; Brennecke and Eckert, 1989). Carbon dioxide is a promising solvent since it is inexpensive, nontoxic, inflammable, and environmentally acceptable and has a low critical

\footnotetext{
* To whom correspondence should be addressed.
}

temperature and a moderate critical pressure. The design and development of supercritical extraction processes also depend on the ability to model and predict the solubilities of solid solutes in supercritical solvents. The prediction is usually difficult because of the large differences in sizes and molecular interactions between the solute and solvent molecules.

Cubic type equations of state (EOS), which have been extensively applied in vapor-liquid equilibrium (VLE) calculations, have also been used in computing the solubilities of solids in supercritical fluids (A review paper on 
modeling supercritical mixtures was given by Johnston et al. (1989)). Haselow et al. (1986) have evaluated nine cubic equations of state regarding their abilities in SCFE calculations. They suggested that there is a need to develop new mixing rules. Otherwise, no existing cubic equations of state with traditional van der Waals mixing rules can yield good solubility results. Eckert et al. $(1983,1986)$ have examined the behavior of the infinite negative value of the partial molar volume of solutes in supercritical fluids. They also concluded that the EOS model can predict the partial molar volumes accurately only when proper mixing rules are applied.

In this study, we propose that the solubilities of aromatic solids in supercritical carbon dioxide be calculated by using the Patel-Teja EOS. Unlike the traditional van der Waals mixing rules, we evaluate the energy parameter of the EOS with a method suggested by Huron and Vidal (1979). A modification for the mixing rule of the excluded volume parameter has also been presented. Satisfactory calculation results can be obtained by the improved mixing rules, and the results are compared to those using the traditional van der Waals mixing rules.

\section{Solubility of Solid Solute in Supercritical Fluid}

The general phase equilibrium equation for a solid-supercritical fluid mixture is

$$
f_{2}=\hat{f}_{2}^{\mathrm{scf}}
$$

where subscript 2 indicates the heavy solute component. The solid phase is considered to be pure, and the nonideal behavior is entirely in the supercritical phase.

The fugacity of a pure solid at a given temperature and pressure is expressed as

$$
f_{2}^{\delta}=P_{2}^{\text {sat. }} \phi_{2}^{\text {gat.,s }} \exp \left[\frac{V_{2}^{\text {s }}\left(P-P_{2}^{\text {kat. }}\right)}{R T}\right]
$$

The fugacity coefficient of a saturated solid, $\phi_{2}^{\text {sat.,s }}$, is taken to be 1.0 at low solid vapor pressures.

The fugacity of a solute in the supercritical phase is

$$
\hat{f}^{\text {scf }}=y_{2} \hat{\phi}_{2}^{\text {scf }} P
$$

From the combination of eqs 2 and 3 , the solubility of a solid is expressed as

$$
y_{2}=\frac{P_{2}^{\text {aat. }} \exp \left[V_{2}^{\text {s }}\left(P-P_{2}^{\text {at. }}\right) / R T\right]}{\hat{\phi}_{2}^{\text {scf }} P}
$$

The fugacity coefficient, $\hat{\phi}_{2}^{\text {scf }}$, is calculated by an EOS. The accuracy of solubility computations depends on the proper mixing rules to evaluate the fugacity coefficient.

\section{Equation of State and the Mixing Rules}

In this study, the fugacity coefficient is calculated by the Patel-Teja EOS (Patel and Teja, 1982):

$$
P=\frac{R T}{V-b}-\frac{a}{V^{2}+(b+c) V-b c}
$$

For mixture calculations, the following van der Waals mixing rules are conventionally applied for cubic type equations of state:

$$
\begin{gathered}
a_{\mathrm{m}}=\sum_{i} \sum_{j} x_{i} x_{j}\left(a_{i} a_{j}\right)^{1 / 2} k_{i j} \\
b_{\mathrm{m}}=\sum_{i} \sum_{j} x_{i} x_{j}\left(\frac{b_{i}+b_{i}}{2}\right) l_{i j} \\
c_{\mathrm{m}}=\sum_{i} \sum_{j} x_{i} x_{j}\left(\frac{c_{i}+c_{i}}{2}\right) m_{i j}
\end{gathered}
$$

where $k_{i j}, l_{i j}$, and $m_{i j}$ are adjustable unlike interaction parameters. These parameters are fitted by using the experimental data. They cannot be predicted or correlated and may have different values at various temperatures. Kwak and Mansoori (1986) have shown these parameters when they applied the Peng-Robinson EOS in supercritical fluid extraction modeling.

Improved methods have been proposed to evaluate the EOS parameters without using empirically adjustable parameters. The model presented by Huron and Vidal (1979) is a good example. They assumed that no excess volume exists at an infinite pressure limit and determined the energy parameter by equating the Gibbs free energy calculated by the EOS to that of a liquid model. This approach is employed by many investigators (e.g., Tochigi et al. (1985), Pandit and Singh (1987), and Huang (1990), etc.) to correlate nonideal mixtures. On the basis of Huron and Vidal's model, Sheng et al. (1989) and Suen et al. (1989) also have applied the Patel-Teja EOS and the UNIFAC group contribution liquid model (Fredenslund et al., 1977; Larsen et al., 1987) to VLE and multiphase equilibrium calculations, respectively. Their method is extended to solid-supercritical fluid mixtures in this study.

In this research, we calculate the excess Helmholtz free energy from the Patel-Teja EOS at an infinite pressure limit:

$$
\left(\frac{A^{\mathrm{E}}}{R T}\right)_{P=\infty}=\frac{a_{\mathrm{m}} Q Q_{\mathrm{m}}}{2 R T N_{\mathrm{m}}}=\sum_{i} \frac{x_{i} a_{i} Q Q_{i}}{2 R T N_{i}}
$$

where

$$
\begin{gathered}
N=\left[b c+\frac{(b+c)^{2}}{4}\right]^{1 / 2} \\
Q Q=\ln \left[\frac{3 b+c-2 N}{3 b+c+2 N}\right]
\end{gathered}
$$

The excess Helmholtz free energy of a group contribution liquid model, like UNIFAC, is assigned to the excess Helmholtz free energy expression in eq 9. The EOS parameter, $a_{m}$, can then be determined from eq 9 and the group contribution liquid model. The excess Helmholtz free energy equation from the UNIFAC model is written in a pressure-independent form and is usually taken as equal to the expression of the excess Gibbs free energy.

Huron and Vidal (1979) assumed that no excess volume exists at an infinite pressure limit and determined the volume parameter, $b_{\mathrm{m}}$, by a simple van der Waals mixing rule. This assumption is good for VLE, liquid-liquid equilibrium, or multiphase equilibrium calculations (Sheng et al., 1989; Suen et al., 1989), but we found in this research that it is not adequate for solid-supercritical fluid mixtures. We propose a modification on the volume parameter by including an excess term beyond the simple van der Waals mixing rule

$$
b_{\mathrm{m}}=\sum_{i} x_{i} b_{i}+b^{\mathrm{E}}
$$

and we express the composition dependence of the excess term by a three-suffix Margulus-type equation:

$$
b^{\mathrm{E}}=x_{1} x_{2}\left(K_{1}+K_{2} x_{2}\right)
$$

where $K_{1}$ and $K_{2}$ are two constants, which are to be fitted as functions of the characteristic properties of pure solute.

Following the new mixing rule, we can express the fugacity coefficient of component $i$ in a mixture as 
$R T \ln \hat{\phi}_{i}^{\text {sf }}=$

$$
\begin{gathered}
\left(R T \hat{b}_{i} /\left(V-b_{\mathrm{m}}\right)\right)+\left(\hat{a}_{i} \ln \left(Q Q_{\mathrm{m}}\right) / 2 N_{\mathrm{m}}\right)-\left[a _ { \mathrm { m } } \left[V \left(b_{\mathrm{m}} \hat{b}_{i}+\right.\right.\right. \\
\left.c_{\mathrm{m}} \hat{c}_{i}+3 \hat{b}_{i} c_{\mathrm{m}}+3 b_{\mathrm{m}} \hat{c}_{i}\right)+\left(b_{\mathrm{m}}{ }^{2} b_{i}+c_{\mathrm{m}}{ }^{2} c_{i}+3 b_{\mathrm{m}} b_{i} c_{\mathrm{m}}+\right. \\
\left.\left.\left.3 b_{\mathrm{m}} c_{\mathrm{m}} c_{i}\right)\right] /\left(4 N_{\mathrm{m}}{ }^{2}\left[V^{2}+\left(b_{\mathrm{m}}+c_{\mathrm{m}}\right) V-b_{\mathrm{m}} c_{\mathrm{m}}\right]\right)^{1 / 2}\right]+ \\
{\left[\left(a_{\mathrm{m}}\left(b_{\mathrm{m}} \hat{b}_{i}+c_{\mathrm{m}} \hat{c}_{i}+3 \hat{b}_{i} c_{\mathrm{m}}+3 b_{\mathrm{m}} \hat{c}_{i}\right) \ln \left(Q Q_{\mathrm{m}}\right)\right) /\left(4 N_{\mathrm{m}}\right)^{2 / 3}\right]}
\end{gathered}
$$

where

$$
\begin{gathered}
\hat{a}_{i}=n^{-1}\left(\partial n^{2} a_{\mathrm{m}} / \partial n_{i}\right)_{T, V, n_{j}} \\
\hat{b}_{i}=\left(\partial n b_{\mathrm{m}} / \partial n_{i}\right)_{T, V, n_{j}} \\
\hat{c}_{i}=\left(\partial n c_{\mathrm{m}} / \partial n_{i}\right)_{T, V, n_{j}}
\end{gathered}
$$

The energy and volume parameters $a_{\mathrm{m}}$ and $b_{\mathrm{m}}$ are expressed by eqs 9,12 , and 13 , respectively. $c_{\mathrm{m}}$ is written in a simple van der Waals form as

$$
c_{\mathrm{m}}=\sum_{i} x_{i} c_{i}
$$
by

The partial molar volume of the solute can be expressed

$$
\hat{V}_{i}=-\frac{n\left(\partial P / \partial n_{i}\right)_{T, V, n_{j}}}{\left(\partial P / \partial V_{T, \text { all } n}\right.}
$$

where

$$
\begin{aligned}
& \left(\frac{\partial P}{\partial V}\right)_{T, \text { all n }}= \\
& \quad-\frac{R T}{\left(V-b_{\mathrm{m}}\right)^{2}}+\frac{a_{\mathrm{m}}\left(2 V+b_{\mathrm{m}}+c_{\mathrm{m}}\right)}{\left[V^{2}+\left(b_{\mathrm{m}}+c_{\mathrm{m}}\right) V-b_{\mathrm{m}} c_{\mathrm{m}}\right]^{2}}(20) \\
& n\left(\frac{\partial P}{\partial n_{i}}\right)_{T, V, n_{j}}=\frac{R T}{V-b_{\mathrm{m}}}+\frac{R T \hat{b}_{i}}{\left(V-b_{\mathrm{m}}\right)^{2}}+ \\
& \frac{\hat{a}_{i}}{V^{2}+\left(b_{\mathrm{m}}+c_{\mathrm{m}}\right) V-b_{\mathrm{m}} c_{\mathrm{m}}}-\frac{a_{\mathrm{m}}\left[V\left(\hat{b}_{i}+\hat{c}_{i}\right)-b_{\mathrm{m}} \hat{c}_{i}-\hat{b}_{i} c_{\mathrm{m}}\right]}{\left[V^{2}+\left(b_{\mathrm{m}}+c_{\mathrm{m}}\right) V-b_{\mathrm{m}} c_{\mathrm{m}}\right]^{2}}
\end{aligned}
$$

\section{Modified UNIFAC Group Contribution Liquid Model}

We apply a modified UNIFAC group contribution liquid model to calculate the energy parameter of the EOS by eq 9. The modified combinatorial part of the UNIFAC equation suggested by Sheng et al. (1989) is used

\begin{tabular}{|c|c|c|c|}
\hline group pairs, $i-j^{a}$ & $A_{i j, 1}$ & $A_{i j, 2}$ & $A_{i j, 3}$ \\
\hline $\mathrm{CO}_{2}-\mathrm{CH}_{4}$ & 516.2 & 9.409 & -22.62 \\
\hline $\mathrm{CH}_{4}-\mathrm{CO}_{2}$ & -336.2 & -13.89 & 45.41 \\
\hline $\mathrm{CO}_{2}-\mathrm{CH}_{2}$ & 467.2 & 6.551 & 10.88 \\
\hline $\mathrm{CH}_{2}-\mathrm{CO}_{2}$ & -2.825 & -2.719 & -4.085 \\
\hline $\mathrm{CO}_{2}-\mathrm{ACH}$ & 129.3 & -0.347 & -1.914 \\
\hline $\mathrm{ACH}-\mathrm{CO}_{2}$ & 4.162 & 0.288 & -0.358 \\
\hline $\mathrm{CO}_{2}-\mathrm{ACCH}_{2}$ & 388.5 & -0.48 & 1.367 \\
\hline $\mathrm{ACCH}_{2}-\mathrm{CO}_{2}$ & -112.2 & -0.867 & -0.407 \\
\hline $\mathrm{CO}_{2}-\mathrm{NAC}$ & 455.6 & -2.317 & -3.065 \\
\hline $\mathrm{NAC}-\mathrm{CO}_{2}$ & 1304 & 0.256 & 0.150 \\
\hline $\mathrm{ACH}-\mathrm{ACCH}_{2}$ & 167.0 & 0 & 0 \\
\hline $\mathrm{ACCH}_{2}-\mathrm{ACH}$ & -146.8 & 0 & 0 \\
\hline ACH-NAC & 372.2 & 1.340 & 1.486 \\
\hline NAC-ACH & 1.959 & 1.126 & 1.142 \\
\hline $\mathrm{ACCH}_{2}-\mathrm{NAC}$ & 697.6 & 0.542 & 0.657 \\
\hline $\mathrm{NAC}-\mathrm{ACCH}{ }_{2}$ & 582.6 & 0.829 & 0.634 \\
\hline
\end{tabular}

$$
\frac{G^{\mathrm{E}, \mathrm{C}}}{R T}=\sum_{i} x_{i} \ln \left(\frac{\psi_{i}^{\prime}}{x_{i}}\right)-\frac{z}{2} \sum_{i} q_{i} x_{i} \ln \left(\frac{\psi_{i}}{\theta_{i}}\right)
$$

where

$$
\begin{gathered}
\psi_{i}^{\prime}=\frac{x_{i}\left(r_{i}\right)^{p_{i}}}{\sum_{j} x_{j}\left(r_{j}\right)^{p_{j}}} \\
\psi_{i}=\frac{x_{i} r_{i}}{\sum_{j} x_{j} r_{j}} \\
p_{i}=1-\frac{1}{0.8\left(q_{i} r_{i}^{-2 / 3}-1\right)^{1.5}+1} \\
\theta=\frac{x_{i} q_{i}}{\sum_{j} x_{j} q_{j}}
\end{gathered}
$$

The residual part employed in this work is similar to the
Table I. Binary Group Interaction Parameters for Carbon Dioxide and Various Hydrocarbon Groups in the UNIFAC Model

a Abbreviations: $\mathrm{CH}_{4}=$ methane, $\mathrm{CH}_{2}=$ aliphatic $\mathrm{C}, \mathrm{ACH}=$ aromatic $\mathrm{CH}, \mathrm{ACCH}_{2}=$ aromatic $\mathrm{CCH}_{2}, \mathrm{NAC}=$ naphthenic $\mathrm{C}$.

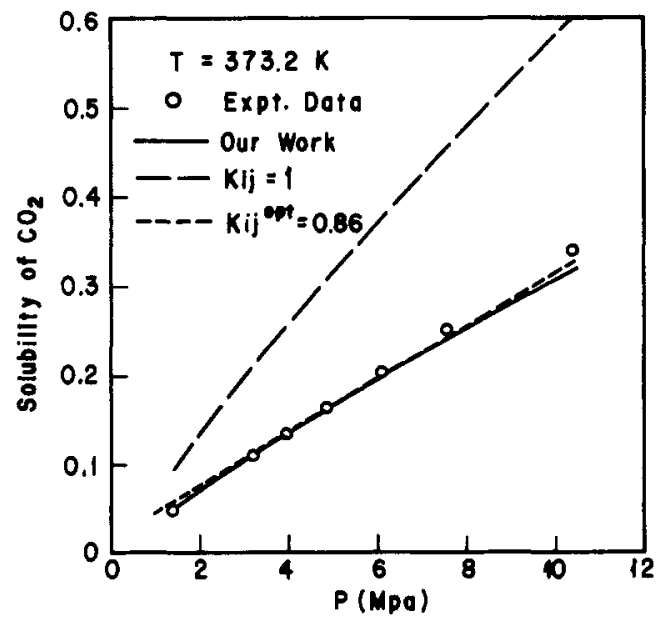

Figure 1. Comparison of solubilities of carbon dioxide in naphthalene calculated by this work and the van der Waals mixing rules at $373.2 \mathrm{~K}$ (experimental data: Barrick et al., 1987).

one presented by Larsen et al. (1987), with group interaction parameter $A_{i j}$ in the following temperature-dependent form:

$A_{i j}=A_{i j, 1}+A_{i j, 2}\left(T-T_{0}\right)+A_{i j, 3}\left(T \ln \left(\frac{T_{0}}{T}\right)+T-T_{0}\right)$

where the reference temperature, $T_{0}$, is $298.15 \mathrm{~K}$. The UNIFAC group interaction parameters are regressed from experimental phase equilibrium data. Since those parameters involving carbon dioxide are not available in literature, they must be evaluated by fitting VLE or gas solubility data of carbon dioxide and hydrocarbon mixtures.

\section{Results and Discussion}

The UNIFAC group interaction parameters for carbon dioxide and hydrocarbons are fitted in this work, and the results are shown in Table I. We use the method suggested by Sheng et al. (1989) to regress those group interaction parameters, and our VLE and gas solubility results on carbon dioxide and hydrocarbon binary systems are shown in Table II. Comparisons of our calculated results with those obtained by traditional van der Waals mixing rules are also shown in Table II and Figures 1 and 2. Good agreement between our results and experimental data is observed. The accuracy of our results is usually 


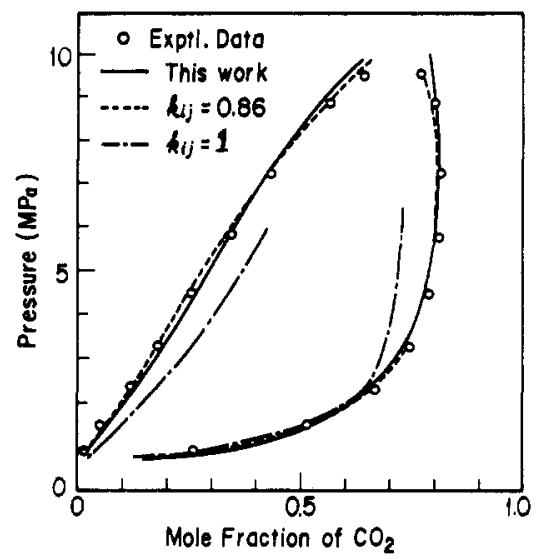

Figure 2. Comparison of the calculated $P-x-y$ curves of carbon dioxide and $n$-pentane by this work and the van der Waals mixing rules at $377.59 \mathrm{~K}$ (experimental data: Besserer and Robinson, 1973).

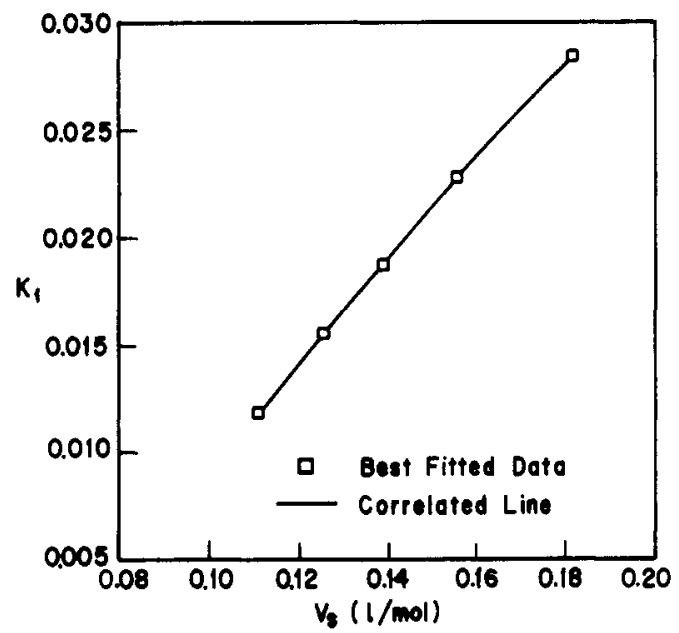

Figure 3. Plot of the parameter $K_{1}$ against the solid molar volumes.

better than that of the van der Waals model with its optimally fitted binary interaction parameters.

Table III gives the physical properties of the five aromatic compounds studied in this work. The critical constants and acentric factors for carbon dioxide and naphthalene are taken from Reid et al. (1987), and those values for other components are taken from Haselow et al. (1986). Solid volumes are taken from Weast (1989), and that of 2,6-dimethylnaphthalene is estimated in this work. Experimental solid vapor pressures are taken from Fowler et al. (1968), Schmitt and Reid (1986), and Osborn and Douslin (1975). The solid vapor pressures are fitted by the Antoine equation, and the parameters are given in Table III. We regress the Patel-Teja EOS parameters $\zeta_{c}$ and $F$ for naphthalene from its saturation data (Fowler et al., 1968). EOS parameters for other compounds are calculated by the correlation equation given by Georgeton et al. (1986).

Parameters $K_{1}$ and $K_{2}$ in the excess volume equation can be fitted in the solubility calculations of the five aromatic compounds in supercritical carbon dioxide. We observe that these parameters are functions of solid molar volumes. The results are shown in Figures 3 and 4, and the functions are expressed as

$$
\begin{aligned}
& K_{1}=-0.0356+0.5275 V^{\mathrm{s}}-0.9408\left(V^{\mathrm{s}}\right)^{2} \\
& K_{2}=10.72-124.135 V^{\mathrm{s}}+248.944\left(V^{\mathrm{s}}\right)^{2}
\end{aligned}
$$

Table IV shows our calculated solubility results. It is again found that our improved mixing rules, with no ad-

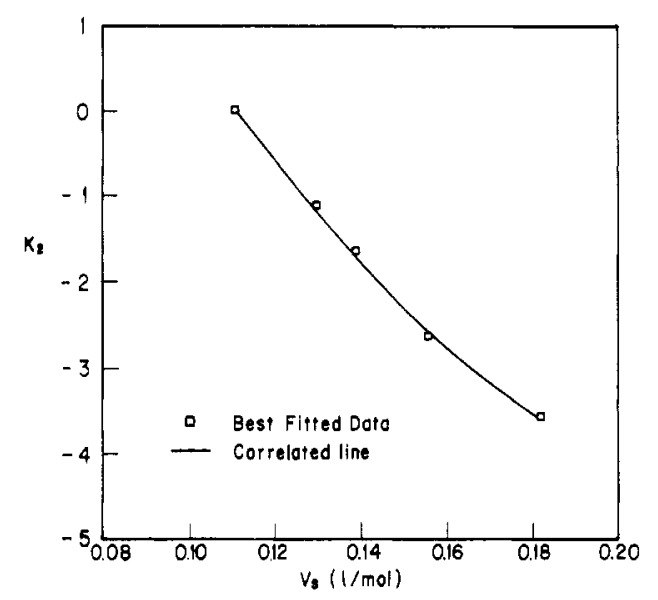

Figure 4. Plot of the parameter $K_{2}$ against the solid molar volumes.

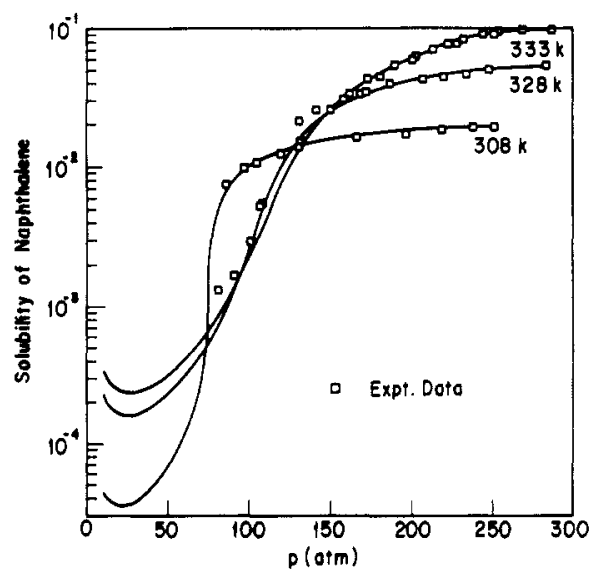

Figure 5. Calculated results of the solubilities of naphthalene in supercritical carbon dioxide by this work (experimental data: McHugh and Paulatis, 1980).

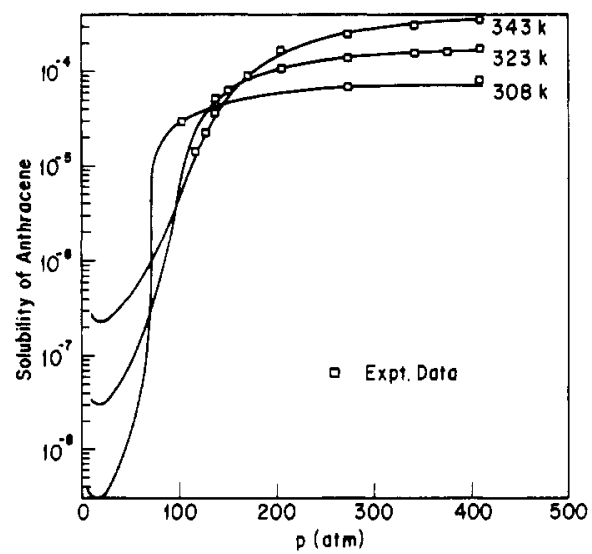

Figure 6. Calculated results of the solubilities of anthracene in supercritical carbon dioxide by this work (experimental data: Johnston et al., 1982).

justable parameters, are superior to the traditional van der Waals mixing rules with optimally fitted unlike pair parameters. Graphical comparisons of experimental and calculated solubilities of naphthalene, anthracene, and phenanthrene at various temperatures are shown in Figures 5-7, respectively.

Figure 8 shows our calculated result of the infinite dilution partial molar volumes of naphthalene in carbon dioxide at $308 \mathrm{~K}$. A sharp negative value is observed close to $78 \mathrm{bar}$, which is in satisfactory agreement with the experimental data of Eckert et al. (1986), where a negative minimum at near 79.7 bar was found. Eckert et al. (1983) have discussed the importance of using proper mixing rules 
Table II. Correlation of Vapor-Liquid Equilibria of Binary Mixtures of Carbon Dioxide and Hydrocarbons

\begin{tabular}{|c|c|c|c|c|c|c|}
\hline \multirow[b]{2}{*}{ hydrocarbons } & \multirow[b]{2}{*}{ no. of data points } & \multirow[b]{2}{*}{ temp range, $\mathrm{K}$} & \multirow[b]{2}{*}{ press. range, atm } & \multicolumn{2}{|c|}{ AADP, ${ }^{w} \%$} & \multirow[b]{2}{*}{ ref } \\
\hline & & & & this work & $\begin{array}{l}\text { van der Waals } \\
\text { mixing rules }\end{array}$ & \\
\hline $\begin{array}{l}\text { methane } \\
n \text {-propane } \\
n \text {-butane } \\
n \text {-pentane } \\
n \text {-decane } \\
n \text {-hexadecane } \\
n \text {-eicosane } \\
\text { benzene } \\
\text { toluene } \\
m \text {-xylene } \\
\text { 1-methylnaphthalene } \\
\text { naphthalene } \\
\text { 1-methylnaphthalene }\end{array}$ & $\begin{array}{c}64 \\
50 \\
24 \\
38 \\
16 \\
16 \\
47 \\
52 \\
49 \\
49 \\
28 \\
14^{v} \\
8^{v}\end{array}$ & $\begin{array}{l}193-270 \\
277-344 \\
310-377 \\
278-377 \\
463-583 \\
463-663 \\
310-373 \\
298-393 \\
311-542 \\
303-543 \\
353-703 \\
373-423 \\
300-475\end{array}$ & $\begin{array}{c}14-85 \\
10-61 \\
4-71 \\
2-95 \\
19-50 \\
20-50 \\
5-75 \\
9-131 \\
3-150 \\
3-170 \\
8-142 \\
14-103 \\
1\end{array}$ & $\begin{array}{l}3.76 \\
3.59 \\
3.74 \\
8.20 \\
2.55 \\
5.37 \\
5.80 \\
2.61 \\
3.12 \\
3.67 \\
3.79 \\
6.61 \\
8.28\end{array}$ & $\begin{array}{c}2.10 \\
6.72 \\
6.78 \\
6.71 \\
3.82 \\
16.7 \\
40.9 \\
55.9 \\
4.14 \\
6.28 \\
3.83 \\
13.8 \\
10.0\end{array}$ & $\begin{array}{l}a-c \\
d, e \\
f, g \\
h \\
i \\
i \\
j \\
k-m \\
n-p \\
0, q, r \\
n, s \\
t \\
u\end{array}$ \\
\hline
\end{tabular}

${ }^{a}$ Donnelly and Katz, 1954. ${ }^{b}$ Somait and Kidnay, 1978. ' Mraw et al., 1978. ${ }^{d}$ Reamer et al., 1951. ${ }^{e}$ Haman and Lu, 1976. $f$ Olds et al., 1949. Besserer and Robinson, 1971. ${ }^{h}$ Besserer and Robinson 1973. ${ }^{i}$ Sebastian et al., 1980a. ${ }^{j}$ Huie et al., 1973. ${ }^{k}$ Ohgaki and Katayama, 1976. 'Gupta et al., 1982. 'm Nagarajan and Robinson, 1987. ${ }^{n}$ Morris and Donohue, 1985. ${ }^{\circ}$ Sebastian et al., $1980 \mathrm{c}$. $P \mathrm{Ng}$ and Robinson, 1978 . ${ }^{9} \mathrm{Ng}$ et al., 1982. 'Vera and Orbey, 1984. 'Sebastian et al., 1980b. 'Barrick et al., 1987. "Tremper and Prausnitz, 1976. 'Gas solubilities are calculated for these systems. ${ }^{x} \mathrm{~A}$ nearly optimal $k_{i j}$ value of 0.9 is used in the van der Waal mixing rule for all systems. ${ }^{w} \mathrm{AADP}=$ $(100 / \mathrm{NP}) \sum_{i}\left|\left(P_{i}^{\text {calc }}-P_{i}^{\text {ozpt }}\right) / P_{i}^{\text {oxpt }}\right| ; \mathrm{NP}=$ number of data points.

Table III. Physical Properties of Five Aromatic Compounds Studied in This Work ${ }^{a}$

\begin{tabular}{llcccc}
\hline & naphthalene & phenanthracene & anthracene & 2,3-dimethylnaphthalene & 2,6-dimethylnaphthalene \\
\hline$T_{\mathrm{c}}, \mathrm{K}$ & $\mathbf{7 4 8 . 4}$ & $\mathbf{8 9 0}$ & 869.3 & 785 & 777 \\
$\boldsymbol{P}_{\mathrm{c}}$, atm & 40 & 32.5 & 34.4 & 31.75 & 31.8 \\
$\omega$ & 0.302 & 0.429 & 0.532 & 0.424 & 0.420 \\
$V_{\mathrm{B}}, \mathrm{L} / \mathrm{mol}$ & 0.111 & 0.182 & 0.139 & 0.1558 & 0.130 \\
$A$ & 9.5810 & 11.420 & 12.630 & 11.910 & 12.357 \\
$B$ & 2619.9 & 4567.7 & 5313.7 & 4292.1 & 0.0 \\
$C$ & 52.50 & 0.0 & 0.0 & 0.0 & 0.3005 \\
$\zeta_{\mathrm{c}}$ & 0.307 & 0.333 & 0.294 & 0.3003 & 0.95047 \\
$F$ & 0.82539 & 0.95986 & 1.06550 & 0.95461 &
\end{tabular}

a The solid vapor pressures are fitted to a function of $\log (P$ at $/ \mathrm{mmHg})=A-B /[(T / K)-C]$.

Table IV. Correlation of Aromatic Solid Solubilities in Supercritical Carbon Dioxide

\begin{tabular}{|c|c|c|c|c|c|c|c|}
\hline \multirow[b]{2}{*}{ aromatic compd } & \multirow[b]{2}{*}{ no. of data points } & \multirow[b]{2}{*}{ temp range, $\mathrm{K}$} & \multirow[b]{2}{*}{ press. range, $\mathrm{MPa}$} & \multicolumn{3}{|c|}{ AADY, ${ }^{d} \%$} & \multirow[b]{2}{*}{ ref } \\
\hline & & & & this work & (II) & (I) & \\
\hline $\begin{array}{l}\text { naphthalene } \\
\text { 2,3-dimethylnaphthalene } \\
\text { 2,6-dimethylnaphthalene } \\
\text { anthracene } \\
\text { phenanthrene }\end{array}$ & $\begin{array}{l}44 \\
14 \\
15 \\
21 \\
15\end{array}$ & $\begin{array}{l}308-333 \\
308-328 \\
308-328 \\
308-343 \\
318-338\end{array}$ & $\begin{array}{r}9-30 \\
10-30 \\
10-30 \\
9-42 \\
8-42\end{array}$ & $\begin{array}{l}6.12 \\
5.40 \\
7.04 \\
7.00 \\
7.82\end{array}$ & $\begin{array}{r}6.79 \\
6.98 \\
16.49 \\
8.72 \\
7.57\end{array}$ & $\begin{array}{r}40.07 \\
8.77 \\
23.35 \\
14.41 \\
15.46\end{array}$ & $\begin{array}{l}a \\
b \\
b \\
c \\
b\end{array}$ \\
\hline
\end{tabular}

${ }^{a}$ McHugh and Paulatis, 1980. ${ }^{b}$ Kurnik et al., 1981. ' Johnston et al., 1982. ${ }^{d}$ AADY $=(100 / N P)\left|\left(y_{2}^{\text {calc }}-y_{2}^{\text {expt }}\right) / y_{2}^{\text {expt }}\right|$; NP $=$ number of data points. AADY(I): van der Waals mixing rules with one optimal adjustable parameter $k_{i j}^{\text {opt. }}$. AADY(II): van der Waals mixing rules with two adjustable parameters $k_{i j}^{\text {opt. }}$ and $l_{i j}^{\text {opt. }}$.

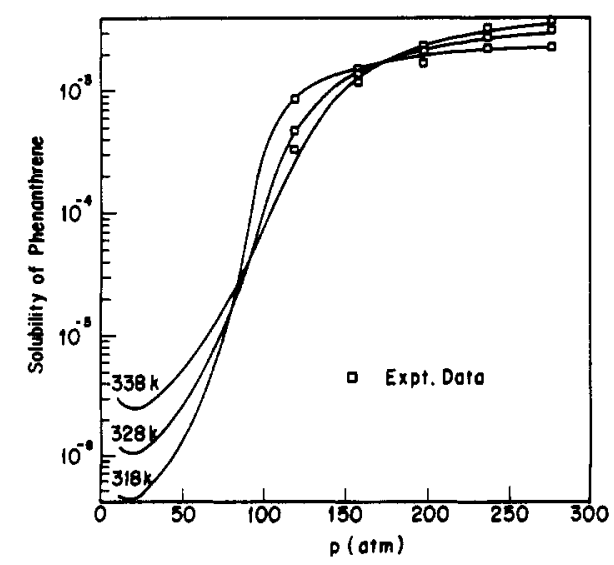

Figure 7. Calculated results of the solubilities of phenanthrene in supercritical carbon dioxide by this work (experimental data: Kurnik et al., 1981).

to correlate the partial molar volume data. The agreement shown in Figure 8 indicates that our improved mixing rules

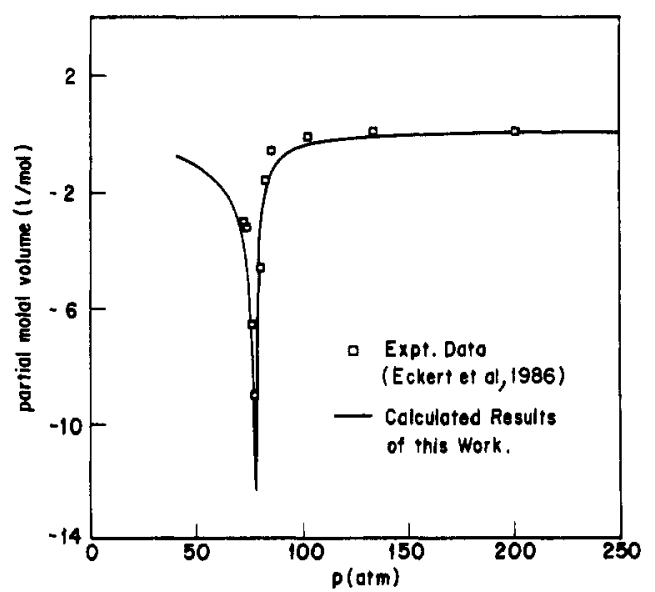

Figure 8. Calculated results of the partial molar volumes of naphthalene in supercritical carbon dioxide at $308 \mathrm{~K}$ by this work (experimental data: Eckert et al., 1986).

are suitable in modeling the phase equilibria of solid and supercritical fluid mixtures. Further calculations of the 
solubilities of biological compounds in supercritical carbon dioxide are currently undergoing.

\section{Conclusions}

Solid solubilities of five aromatic compounds in supercritical carbon dioxide are calculated by using the PatelTeja EOS and the improved mixing rules. This study suggests a generalized method, with no adjustable parameters for each binary system, to calculate the solid solubilities in supercritical fluids. The results of this work are comparable to those by using the traditional van der Waals mixing rules with multiple best-fitted unlike pair parameters. This improved method can also give satisfactory predictions of partial molar volumes of solute in supercritical solvent.

\section{Acknowledgment}

We are grateful to the National Science Council, Republic of China, for supporting this research. Partial results of this work have been presented at the 40th Canadian Chemical Engineering Conference, Halifax, Nova Scotia, 1990.

\section{Nomenclature}

$A=$ temperature coefficient of the UNIFAC group interaction parameters, or the parameter in the vapor pressure equation, or the Helmholtz free energy

$B, C=$ parameters in the vapor pressure equation

$a, b, c=$ equation of state parameters

$\hat{a}, \hat{b}, \hat{c}=$ partial derivatives defined in eqs $15-17$

$F=$ parameter in the Patel-Teja equation of state

$f=$ fugacity

$G=$ Gibbs free energy

$K_{1}, K_{2}=$ parameters in eq 13

$k, l, m=$ unlike pair factors defined in eqs $6-8$, respectively

$n=$ number of moles

$P=$ pressure

$p=$ exponent defined in eqs 23 and 25

$q, r=$ surface area and volume parameters in the UNIFAC model, respectively

$R=$ gas constant

$T=$ temperature

$T_{0}=$ reference temperature of $298.15 \mathrm{~K}$

$V=$ volume

$x, y=$ mole fractions

$z=$ coordination number

\section{Greek Letters}

$\psi, \psi=$ volume fractions defined in eqs 23 and 24 , respectively

$\theta=$ surface fraction defined in eq 26

$\zeta_{\mathrm{c}}=$ parameter in the Patel-Teja equation of state

$\phi=$ fugacity coefficient

$\omega=$ acentric factor

\section{Superscripts}

$\mathrm{C}=$ combinatorial contribution

$\mathrm{E}=$ excess property

$8=$ solid phase

sat. = saturation condition

scf $=$ supercritical phase

\section{Subscripts}

2 = solute component

$c=$ critical property

$i, j=$ general component of group indexes

$\mathrm{m}=$ mixture property

Registry No. $\mathrm{CO}_{2}, 124-38-9$; naphthalene, 91-20-3; phenanthrene, 85-01-8; 2,3-dimethylnaphthalene, 581-40-8; 2,6-dimethylnaphthalene, 581-42-0.

\section{Literature Cited}

Barrick, N. W.; Anderson, J. M.; Robinson, R. L. Solubilities of Carbon Dioxide in Naphthalene, Phenanthrene, and Pyrene at Pressures to $1.6 \mathrm{MPa}$ and Temperatures from 373 to $433 \mathrm{~K}$. J. Chem. Eng. Data 1987, 32, 372-374.

Besserer, G. J.; Robinson, D. B. A High Pressure Autocollimating Refractomer for Determining Coexisting Liquid and Vapor Phase Densities. Can. J. Chem. Eng. 1971, 49,651-656.

Besserer, G.; Robinson, D. B. Equilibrium-Phase Properties of $n$ Pentane-Carbon Dioxide System. J. Chem. Eng. Data 1973, 18, 416-419.

Brennecke, J. F.; Eckert, C. A. Phase Equilibria for Supercritical Fluid Process Design. AIChE J. 1989, 35, 1409-1427.

Donnelly, H. G.; Katz, D. L. Phase Equilibria in the Carbon Dioxide-Methane System. Ind. Eng. Chem. 1954, 46, 511-517.

Eckert, C. A.; Ziger, D. H.; Johnston, K. P.; Ellison, T. K. The Use of Partial Molar Volume Data to Evaluate Equations of State for Supercritical Fluid Mixtures. Fluid Phase Equilib. 1983, 14, $167-175$.

Eckert, C. A.; Ziger, D. H.; Johnston, K. P.; Kim, S. Solute Partial Molar Volumes in Supercritical Fluids. J. Phys. Chem. 1986, 90, 2738-2746.

Fowler, L.; Trump, W. N.; Vogler, C. E. Vapor Pressure of Naphthalene. J. Chem. Eng. Data 1968, 13, 209-210.

Fredenslund, A.; Gmehling, J.; Rasmussen, P. Vapor-Liquid Equilibria Using UNIFAC; Elsevier: New York, 1977.

Georgeton, G. K.; Smith, R. L.; Teja, A. S. Application of Cubic Equations of State to Polar Fluids and Fluid Mixtures. ACS Symp. Ser. 1986, 300, 434-451.

Gupta, M. K.; Li, Y. H.; Hulsey, B. L.; Robinson, R. L. Phase Equilibria for Carbon Dioxide-Benzene at 313.2, 353.2, and 393.2 K. J. Chem. Eng. Data 1982, 27, 55-57.

Hamam, S. E. M.; Lu, B. C.-Y. Isothermal Vapor-Liquid Equilibria in Binary Propane-Carbon Dioxide. J. Chem. Eng. Data 1976, $21,200-204$.

Haselow, J. S.; Han, S. J.; Chao, K. C. Equation of State for Supercritical Fluid Extraction. ACS Symp. Ser. 1986, 300, 156-178.

Huang, H. A New Mixing Rule for the Patel-Teja Equation of State: Study of Vapor-Liquid Equilibria. Fluid Phase Equilib. 1990, 58, 93-115.

Huie, N. C.; Luks, K. D.; Kohn, J. P. Phase Equilibria Behavior of Systems Carbon Dioxide- $n$-Eicosane and Carbon Dioxide- $n$-Decane-n-Eicosane. J. Chem. Eng. Data 1973, 18, 311-313.

Huron, M. J.; Vidal, J. New Mixing Rules in Simple Equations of State for Representing Vapor-Liquid Equilibria of Strongly Nonideal Mixtures. Fluid Phase Equilib. 1979, 3, 255-271.

Johnston, K. P.; Ziger, D. H.; Eckert, C. A. Solubilities of Hydrocarbon Solids in Supercritical Fluids. The Augmented van der Waals Treatment. Ind. Eng. Chem. Fundam. 1982, 21, 191-197.

Johnston, K. P.; Peck, D. G.; Kim, S. Modeling Supercritical Mixtures: How Predictive Is It? Ind. Eng. Chem. Res. 1989, 28, 1115-1125.

Kurnik, R. T.; Holla, S. J.; Reid, R. C. Solubilities of Solids in Supercritical Carbon Dioxide and Ethylene. J. Chem. Eng. Data $1981,26,47-51$.

Kwak, T. Y.; Mansoori, G. A. van der Waals Mixing Rules for Cubic Equations of State: Applications for Supercritical Fluid Extraction Modeling. Chem. Eng. Sci. 1986, 41, 1301-1309.

Larsen, B. L.; Rasmussen, P.; Fredenslund, A. A Modified UNIFAC Group Contribution Model for Prediction of Phase Equilibria and Heats of Mixing. Ind. Eng. Chem. Res. 1987, 26, 2274-2286.

McHugh, M. A.; Paulaitis, M. E. Solid Solubilities of Naphthalene and Biphenyl in Supercritical Carbon Dioxide. J. Chem. Eng. Data 1980, 25, 326-329.

McHugh, M. A.; Krukonis, V. J. Supercritical Fluid Extraction. Principles and Practice; Butterworth: Boston, MA, 1986.

Morris, W. O.; Donohue, M. D. Vapor-Liquid Equilibria in Mixtures Containing Carbon Dioxide, Toluene, and 1-Methylnaphthalene. J. Chem. Eng. Data 1985, 30, 259-263.

Mraw, S. C.; Huang, S. C.; Kobayashi, R. Vapor-Liquid Equilibrium of the $\mathrm{CH}_{4}-\mathrm{CO}_{2}$ System at Low Temperatures. J. Chem. Eng. Data 1978, 23, 135-139.

Nagarajan, N.; Robinson, R. L. Equilibrium Phase Compositions, Phase Densities, and Interfacial Tensions for $\mathrm{CO}_{2}+\mathrm{Hydrocarbon}$ Systems. 3. $\mathrm{CO}_{2}+$ Cyclohexane. 4. $\mathrm{CO}_{2}+$ Benzene. J. Chem. Eng. Data 1987, 32, 369-371.

Ng, H. J.; Robinson, D. B. Equilibrium Phase Properties of the Toluene-Carbon Dioxide System. J. Chem. Eng. Data 1978, 23, 325-327. 
Ng, H. J.; Huang, S. S. S.; Robinson, D. B. Equilibrium Phase Properties of Selected $m$-Xylene Binary Systems, $m$-XyleneMethane and $m$-Xylene-Carbon Dioxide. J. Chem. Eng. Data 1982, 27, 119-122.

Ohgaki, K.; Katayama, T. Isothermal Vapor-Liquid Equilibrium Deta for Binary Systems Containing Carbon Dioxide at High Pressures: Methanol-Carbon Dioxide, $n$-Hexane-Carbon Dioxide, and Benzene-Carbon Dioxide Systems. J. Chem. Eng. Data 1976, $21,53-55$.

Olds, R. H.; Reamer, H. H.; Sage, B. H.; Lacey, W. N. Phase Equilibria in Hydrocarbon Systems. The $n$-Butane-Carbon Dioxide System. Ind. Eng. Chem. 1949, 41, 475-482.

Osborn, A. G.; Douslin, D. R. Vapor Pressures and Derived Enthalpies of Vaporization for Some Condensed-Ring Hydrocarbons. J. Chem. Eng. Data 1975, 20, 229-231.

Pandit, A.; Singh, R. P. Vapor-Liquid Equilibrium Calculations for Polar Mixtures with Mixing Rules Using the ASOG Group Contribution Method. Fluid Phase Equilib. 1987, 33, 1-12.

Patel, N. C.; Teja, A. S. A New Cubic Equation of State for Fluid and Fluid Mixtures. Chem. Eng. Sci. 1982, 37, 463-473.

Reamer, H. H.; Sage, B. H.; Lacey, W. N. Phase Equilibria in Hydrocarbon Systems. Volumetric and Phase Behavior of the Propane-Carbon Dioxide System. Ind. Eng. Chem. 1951, 43, 2515-2520.

Reid, R. C.; Prausnitz, J. M.; Poling, B. E. The Properties of Gases and Liquids, 4th ed.; McGraw-Hill: New York, 1987.

Schmitt, W. J.; Reid, R. C. Solubilities of Monofunctional Organic Solids in Chemically Diverse Supercritical Fluids. J. Chem. Eng. Data 1986, 31, 204-212.

Sebastian, H. M.; Simnick, J. J.; Lin, H. M.; Chao, K. C. VaporLiquid Equilibrium in Binary Mixtures of Carbon Dioxide $+n$ Decane and Carbon Diozide $+n$-Hexadecane. J. Chem. Eng. Data 1980a, 25, 138-140.
Sebastian, H. M.; Nageshwar, G. D.; Lin, H. M.; Chao, K. C. Vapor-Liquid Equilibrium in Binary Mixtures of Carbon Dioxide + Diphenylmethane and Carbon Dioxide + 1-Methylnaphthalene. J. Chem. Eng. Data 1980b, 25, 145-147.

Sebastian, H. M.; Simnick, J. J.; Lin, H. M.; Chao, K. C. Gas-Liquid Equilibrium in Mixtures of Carbon Dioxide + Toluene and Carbon Dioxide $+m$-Xylene. J. Chem. Eng. Data 1980c, 25, 246-248.

Sheng, Y. J.; Chen, Y. P.; Wong, D. S. H. A Cubic Equation of State for Predicting Vapor-Liquid Equilibria of Hydrocarbon Mixtures Using a Group Contribution Mixing Rule. Fluid Phase Equilib. 1989, 46, 197-210.

Somait, F. A.; Kidnay, A. J. Liquid-Vapor Equilibria at $270.00 \mathrm{~K}$ for System Containing Nitrogen, Methane, and Carbon Dioxide. $J$. Chem. Eng. Data 1978, 23, 301-305.

Suen, S. Y.; Chen, Y. P.; Wong, D. S. H. Calculation of Multiphase Equilibria by a Group Contribution Equation of State. Fluid Phase Equilib. 1989, 52, 75-82.

Tochigi, K.; Kurihara, K.; Kojima, K. Prediction of High Pressure Vapor-Liquid Equilibrium with Mixing Rule Using ASOG Group Contribution Method. J. Chem. Eng. Jpn. 1985, 18, 60-65.

Tremper, K. K.; Prausnitz, J. M. Solubility of Inorganic Gases in High-Boiling Hydrocarbon Solvents. J. Chem. Eng. Data 1976, $21,295-299$.

Vera, J. H.; Orbey, H. Binary Vapor-Liquid Equilibria of Carbon Dioxide with 2-Methyl-1-pentene, 1-Hexene, 1-Heptene, and $m$-Xylene at $303.15,323.15$, and $343.15 \mathrm{~K}$. J. Chem. Eng. Data 1984, 29, 269-272.

Weast, R. C., Ed. CRC Handbook of Chemistry and Physics, 69th ed.; CRC Press: Boca Raton, FL, 1989.

Received for review November 18, 1991 Accepted November 27, 1991

\title{
Polymer Solution Properties of a Phenol-Formaldehyde Resol Resin by Gel Permeation Chromatography, Intrinsic Viscosity, Static Light Scattering, and Vapor Pressure Osmometric Methods
}

\author{
Moon G. Kim, ${ }^{*, \dagger}$ World L. Nieh, ${ }^{\dagger}$ Terry Sellers, Jr., ${ }^{\dagger}$ and Wilbur W. Wilson ${ }^{\dagger}$ \\ Forest Products Laboratory and Department of Chemistry, Mississippi State University, Mississippi State, \\ Mississippi 39762 \\ Jimmy W. Mays \\ Department of Chemistry, University of Alabama at Birmingham, Birmingham, Alabama 35294
}

A plywood adhesive-type phenol-formaldehyde (PF) resol resin was shown to have structures generally described as polymeric methylene(hydroxymethyl)phenols as determined by ${ }^{13} \mathrm{C} N \mathrm{NMR}$, and static light scattering gave molecular weights of up to about 114000 daltons. The molecular weight and intrinsic viscosity data resulted in a Mark-Houwink exponent of 0.21 in tetrahydrofuran and 0.15 in ethyl acetate, which indicated a compact molecular structure in solution due to branching of the polymer chain. With the molecular weight and intrinsic viscosity data, the gel permeation chromatographic results obtained on a cross-linked polystyrene gel in tetrahydrofuran gave a universal calibration curve that agreed well with a similar curve obtained for linear polystyrene standards. This work determined the molecular weight and extent of branching of a wood adhesive PF resol resin synthesized by sodium hydroxide catalysis.

\section{Introduction}

The alkaline phenol-formaldehyde (PF) resol resins used extensively as binders in the wood products industry are polymeric methylene(hydroxymethyl)phenols of varying molecular weights (Figure 1). Molecular properties of these resins greatly depend on the synthesis parameters. In wood binder applications, the PF resins are normally

\footnotetext{
${ }^{\dagger}$ Forest Products Laboratory, Mississippi State University.

¥Department of Chemistry, Mississippi State University.
}

synthesized at $60-100^{\circ} \mathrm{C}$ with a formaldehyde/phenol (F/P) ratio of 1.9-2.5, a sodium hydroxide content of up to $0.8 \mathrm{~mol} / \mathrm{mole}$ of phenol, and a resin solids range of $40-60 \%$. Since the resin viscosity must lie within a certain range for most applications, the resin solids level in the reaction mixture has been the major synthesis variable in controlling the molecular weight. In North America, the PF resins used in plywood adhesives normally have a solids level of $40-45 \%$ including the sodium hydroxide catalyst and are among the highest molecular weight PF resins manufactured. 